\title{
FOUNDATIONS FOR LITERACY: EMERGENT LITERACY COMPETENCIES OF GRADE R LEARNERS ON THE CAPE FLATS
}

\author{
Ingrid Willenberg
}

University of the Western Cape

\begin{abstract}
International research has demonstrated that a considerable amount of children's literacy development occurs prior to formal schooling and that emergent literacy skills at school entry are strong predictors of later literacy and general academic achievement. These findings have prompted vigorous early intervention programmes aimed at promoting emergent literacy development to optimise the development of conventional literacy. While there is considerable research conducted in developed countries, there is limited research on the emergent literacy skills of children in South African contexts. In the light of increasing evidence of poor literacy performance of South African children in the foundation phase of schooling it is imperative that appropriate and timely intervention be undertaken. However it is important that intervention be informed by baseline assessments of the children's literacy competencies in the full spectrum of socio-cultural contexts in this diverse country. This study documents the emergent literacy competencies of 101 grade $R$ (the year prior to grade 1, equivalent to kindergarten in the United States) learners attending schools in historically disadvantaged coloured communities on the Cape Flats in the Western Cape. An Emergent Literacy and Language Assessment protocol was developed for use with this population. The children's performance on the assessment tool indicated that in general they possessed a reasonable repertoire of emergent literacy skills. Although they displayed adequate skills to support acquisition of print decoding skills necessary for fluent reading, weaknesses in the decontextualised language skills that have been found to support later reading comprehension, were evident.
\end{abstract}

Key words: emergent literacy, child language, child development, kindergarten, grade R.

\section{INTRODUCTION}

Since the early 1980 s research has demonstrated that children acquire a wealth of knowledge, skills and orientations in relation to reading, writing and oral language prior to receiving formal reading instruction in grade 1 (e.g. Mason, 1980; Lomax $\&$ McGee, 1987). In addition, research has further shown that children's emergent literacy competencies are powerful predictors of their later achievement in literacy as well as in general academic skills (e.g. Tabors, Snow \& Dickinson, 2001). Given the predictive value of emergent literacy skills for later achievement in literacy in particular and academic achievement in general, the United States for example has invested significant resources on early literacy interventions such as Reach Out and Read (http://www.reachoutandread.org) and America Reads (http://www.ed.gov/inits/americareads/index.html).

Undoubtedly South Africa will need to pay urgent attention to promoting emergent literacy development, especially in the light of burgeoning evidence of low literacy achievement of school-going children. A national foundation phase systemic evaluation conducted in 2002 (Department of Education, 2003) on a stratified random sample of 54000 grade 3 learners (equivalent to $5 \%$ of the cohort) found that the average total literacy score obtained was $54 \%$, with the average score for reading comprehension and writing equal to $39 \%$. Similarly, a 2006 study of 82879 Grade 3 learners in the Western Cape found that only $47.7 \%$ demonstrated the appropriate literacy skills expected at Grade 3 level (Western Cape Education Department, 2007). However, before embarking on intervention programmes it is essential to understand the nature and trajec-

\footnotetext{
Address for Correspondence:

Dr. Ingrid A. Willenberg

Faculty of Community \& Health Sciences

University of the Western Cape

Private Bag X17, Bellville, South Africa

Phone: (2721) $9593638 / 2277$

Fax: $\quad$ (2721) 9592845
}

E-Mail: iwillenberg@uwc.ac.za tory of emergent literacy development in local conditions. Unfortunately there is little published research on emergent literacy development of children in South African contexts. The current study investigated emergent literacy development in a local context by assessing the language and literacy competencies of grade $\mathrm{R}$ learners from historically disadvantaged communities in the Western Cape. Prior to introducing the methodology for the study, a brief overview of emergent literacy is provided.

\section{What is emergent literacy?}

The term emergent literacy, initially introduced by Marie Clay (1966), refers to the knowledge, skills and orientations preschoolers display in relation to reading, writing and oral language, prior to receiving formal reading instruction (Sulzby \& Teale, 1991). It is also used with reference to a paradigm of literacy development which differs significantly from earlier theoretical conceptualisations of literacy in that it views literacy development as a continuum beginning at birth and proceeding through the early years of formal schooling, rather than beginning at the onset of formal schooling (Whitehurst \& Lonigan, 1998). The assumptions of the emergent literacy paradigm are: (a) children acquire knowledge about language, reading and writing before receiving formal instruction; (b) reading, writing and oral language develop concurrently and influence each other; (c) the development of literacy occurs in everyday home and community life, in real and purposeful situations; and (d) children experience print independently but benefit from literacy, models in their environment (Teale \& Sulzby, 1986).

Any further discussion regarding literacy must of necessity acknowledge opposing views on the nature of literacy. While traditionally literacy has been regarded as a monolithic entity, with a predominant emphasis on print, this conceptualisation has been challenged by theorists proposing the concept of multiple literacies (e.g. Barton, 1994). However, even proponents of multiple literacies acknowledge that, because literacy is 
shaped by societal power relationships, certain types of literacy, such as conventional school literacy, assume dominance and power over others (Barton \& Hamilton, 1998). So, although it is evident that literacy practices assume a variety of forms in different communities, research has demonstrated that only certain kinds of literacy experiences facilitate the acquisition of conventional literacy. In fact, there is widespread agreement that middle class children tend to be more successful at acquiring literacy skills precisely because their home experiences with literacy tend to endow them with the attitudes, skills and knowledge that enable them to benefit optimally from formal literacy instruction. This begs the question: what are the emergent literacy competencies displayed by children prior to formal reading instruction?

Several systems for classifying these emergent literacy skills exist. Mason and Stewart (1990) identified 4 components of emergent literacy: (1) Concepts and functions of literacy, e.g. knowledge of the functions of print and recognition of environmental print; (2) Writing and composing: word and sentence writing, story composition; (3) Knowledge about letters and words: letter knowledge, phoneme-grapheme correspondence, word recognition, and awareness of sounds in words; and (4) Listening comprehension and word understanding: story retelling, narrative skills, and word definition. Gunn, Simons and Kameenui (1998) proposed a framework of emergent literacy incorporating the following areas: (a) awareness of print; (b) knowledge of the relationship between speech and print; (c) comprehension of text structure; (d) phonological awareness; and (e) letter naming and writing. Awareness of print includes knowing the conventions of print and understanding its uses and purposes. Children's awareness of the relationship between print and speech is realised in their acquisition of letter knowledge and phonological awareness. Knowledge of how written texts in general and written narratives in particular are structured facilitates the comprehension and production of written texts. Whitehurst and Lonigan (1998) proposed a model of both emergent and conventional literacy comprising two mutually dependent sets of skills and processes: "outside-in" and "inside-out". Outside-in processes are important for deriving meaning from print and involve world knowledge, semantic knowledge and knowledge of the written context. Inside-out processes are those which enable children to translate print into sounds and sounds into print, e.g. letter knowledge and phonological processing skills. Inside-out skills are important for decoding and encoding written language, while outside-in skills are essential for deriving meaning from what is read. Essentially, prior to developing conventional literacy children acquire an orientation to print and how it functions; knowledge about letters and sounds and how print maps onto speech; and knowledge of the structure of written language and the ways in which it differs from oral language.

With reference to the classification systems for emergent literacy, an experimental protocol called the Emergent Literacy and Language Assessment Protocol (ELLA) was developed for local use (Willenberg, 2004). The aim of this paper is to document the pilot testing of the protocol and to describe the emergent literacy competencies of the children from historically disadvantaged communities on the Cape Flats in the Western Cape Province.

\section{RESEARCH QUESTION/OBJECTIVES}

The aim of the research was (1) to pilot test the ELLA and (2) to examine and describe the emergent literacy competencies of the children prior to commencing grade 1.

METHODOLOGY

\section{Participants}

The participants in the study were recruited from five schools in the following historically disadvantaged Coloured ${ }^{i}$ communities on the Cape Flats: Kensington, Silvertown, Grassy Park and Mitchell's Plain. No formal selection criteria were employed in identifying schools. Classroom teachers assisted with recruiting the participants. The children considered eligible for the study were those who reached their sixth birthday during the calendar year of the data collection, since 6 years was the official age for admission to grade $\mathrm{R}$ at the time. In addition, children were required to be English speaking. The latter criterion was applied because the protocol was only available in English, and also because of the increased demand for English as a language of instruction on the Cape Flats. The medium of instruction in all the classrooms was English and none of the schools had an Afrikaans-medium grade $\mathrm{R}$ class due to heavy demand by parents for English as a medium of instruction. Children from an Afrikaans background who had limited ability to communicate in English were excluded because they would be disadvantaged by being tested in English. African children from Xhosa-speaking families were also excluded because they did not share similar linguistic or socio-cultural backgrounds with the coloured children. Furthermore, their minority status in the participating schools meant that there would not be a large enough number of children from African, Xhosa-speaking backgrounds to include race and language background as variables in the analysis. Approximately 150 recruitment letters and consent forms were distributed, but after non-returns and refusals, the final sample included 101 children ( 47 boys, 54 girls) ranging from 5 years 7 months to 6 years 10 months, with a mean age of 6 years 2 months.

Since the home and school contexts of the children exert an important influence on their literacy development, a brief overview of these contexts is appropriate here. The family socio-economic backgrounds of the children were mainly working-class and lower middle class. Ten point nine per cent $(10.9 \%)$ of families had a monthly income of less than R3000 and $35.7 \%$ had an income between R3000 and R6999. The average parents in the study both had some high school education and every parent had at least some primary schooling. Thirty-one per cent of both the mothers and fathers had completed secondary school. Approximately half of the parents were not first language speakers of English: $58 \%$ of the mothers and $43 \%$ of the fathers had Afrikaans as the primary language in their own families of origin. In homes where parents were first language speakers of Afrikaans the typical practice was for adults to converse with each other in Afrikaans but speak English to the children. At school, the children were all enrolled in English-medium classrooms ranging in size from 25 to 44 learners per classroom.

Classroom observations revealed a pre-eminence of gross and fine motor activities and perceptual activities, but limited opportunities for rich engagement with language and literacy. Although all classroom routines included a daily story time, children's exposure to good quality books in a variety of genres was extremely limited, as were opportunities to engage in extended discourse around a single topic or to learn new vocabulary. Much of the teacher talk involved attempts to control the children's behaviour and provide instructions for classroom activities and procedures and little discussion was observed.

Procedures 
The ELLA comprises ten sub-tests covering three areas of emergent literacy: (a) orientation to print skills; (b) knowledge of speech-print relationships, and (c) language (See Willenberg, 2004 for a complete description of the administration and scoring procedures). An overview of the sub-tests is presented in Table 1.

The ELLA sub-tests include researcher-developed measures, adaptations of measures use by other researchers, and a standardized test. While the aim was to make the ELLA comprehensive, it could not be exhaustive due to time and resource constraints. The protocol was administered during the last four months of the school year. The assessments were conducted with individual children by a Coloured female researcher in a quiet venue on the school premises. Administration of the complete protocol took approximately 40 minutes, but to avoid challenging the children's ability to concentrate, it was administered over two sessions lasting 20 minutes each. The administration of the sub-tests is described briefly below.

\section{Recognition of Environmental Print}

Each child was presented with several locally familiar logos and signs associated with food products, supermarket chains, a department store, a clothing store, a book store, a restaurant, popular fast food outlets, petrol stations, and telephone service providers.

\section{Clay's Concepts about Print Test}

The original Concepts about Print test (Clay, 1979) was administered. Using the book, Follow Me, Moon (Clay, 2000) as the stimulus, each child was required to demonstrate concepts such as front versus back of book, print direction and orientation, and vocabulary such as page, letter, word and read.

\section{Letter Naming}

Each child was asked to describe the contents of a chart of upper and lower case alphabet letters to determine whether s/he was able to identify the print as letters or ABCs, distinct from numbers. The next instruction was: "Show me any letters you know and tell me their names".

\section{Sounds in Words}

The child was asked to identify from a group of three words, two words with the same initial or final sound (See Appendix A for stimuli). Pic-

Table 1: Sub-Tests of the Emergent Literacy Assessment (ELLA) and the Corresponding Domains of Emergent Literacy

\begin{tabular}{|c|c|c|}
\hline ELLA Measure & Construct/s & Source \\
\hline \multicolumn{3}{|c|}{ Orientation to Print } \\
\hline Environmental Print & $\begin{array}{l}\text { Recognition of environ- } \\
\text { mental print }\end{array}$ & Researcher-developed \\
\hline $\begin{array}{l}\text { Concepts about } \\
\text { print }\end{array}$ & $\begin{array}{l}\text { Knowledge of print con- } \\
\text { cepts }\end{array}$ & Clay (1979) \\
\hline Writing and Spelling & $\begin{array}{l}\text { Concepts about print; } \\
\text { emergent writing; } \\
\text { Invented spelling; phono- } \\
\text { logical awareness }\end{array}$ & $\begin{array}{l}\text { Adapted from Bear, Templeton, } \\
\text { Invernizzi, \& Johnston ( } 2000)\end{array}$ \\
\hline \multicolumn{3}{|c|}{ Knowledge of print-speech relationships } \\
\hline Letter Naming & Alphabet knowledge & Researcher-developed \\
\hline Sounds in Words & Phonological awareness & Mason \& Stewart (1989) \\
\hline Rhyme Recognition & $\begin{array}{l}\text { Phonological Awareness; } \\
\text { rhyme recognition ability }\end{array}$ & $\begin{array}{l}\text { Researcher-developed, based on } \\
\text { the oddities task by Bryant and } \\
\text { Bradley ( } 1978, \text { cited by Bradley, } \\
1990)\end{array}$ \\
\hline Rhyme Production & $\begin{array}{l}\text { Phonological awareness; } \\
\text { rhyme production ability }\end{array}$ & Researcher-developed \\
\hline \multicolumn{3}{|c|}{ Language } \\
\hline $\begin{array}{l}\text { Peabody Picture } \\
\text { Vocabulary Test } \\
\text { (PPVT) }\end{array}$ & Receptive Vocabulary & Dunn \& Dunn (1997) \\
\hline Word Definitions & Definitional skill & $\begin{array}{l}\text { Adapted from the Wechsler Intelli- } \\
\text { gence Scale for Children (WISC- } \\
\text { R)(Wechsler, 1974) }\end{array}$ \\
\hline Fictional Narrative & Narrative production ability & Snow et al. (1995) \\
\hline
\end{tabular}

ture cues were provided to avoid taxing auditory memory. For example, the child was presented with a picture card depicting the words cat, ball and bag. The examiner said each word, while pointing to the corresponding picture and asked: "Show me two that begin with the same sound".

\section{Rhyme Recognition and Production}

Assessment of rhyming skill was modeled on Bryant and Bradley's (Bradley, 1990) oddities task, where children were asked to identify the word in each group that did not rhyme with the rest. On the Rhyme Recognition sub-test, the child was presented with a card containing three pictures, for example, cat, hat and ring. The examiner said the words and pointed to the pictures. The child was then requested to point to the pictures representing the two words that sound "almost the same". Training for this task included the use of three sets of rhyming pairs to illustrate the concept of rhyming words. On the Rhyme Production subtest, 5 of the 10 items in the rhyme recognition task were used. A rhyming pair was said aloud and the child was requested to produce another word that "sounds like" the previous two. (See Appendix B for stimuli)

\section{Emergent Writing and Spelling}

The children's ability to produce invented spelling was assessed using the first two sections of the Primary Spelling Inventory (Bear, Invernizzi, Templeton \& Johnston, 2000). Each child was asked to attempt to write the following words: fat, pen, dig, mop, and rope. If they were able to produce correct or invented spellings they were encouraged to try a few harder words: wait, check, slum, stink, shine. While it was expected that many children would not be able to produce invented spellings, the task nevertheless constituted an attempt to tap their conceptualization of what it means to write. In addition to the spelling inventory, children were also asked to write their name and any words they knew.

\section{Receptive Vocabulary}

The Peabody Picture Vocabulary Test (PPVT III-B) (Dunn \& Dunn, 1997), a standardised, norm-referenced test of receptive vocabulary was administered and scored according to the guidelines prescribed by the authors of the test. Although the use of this test was not ideal, it was included due to the absence of locally standardised measures. The tests items were scrutinised carefully and found not to include Americanisms. However, due to the profusion of American television programmes and films available locally, the use of Americanisms in local parlance has increased dramatically during the past decade, which means that many words considered to be Americanisms are likely to be understood and used by local children. In addition, caution was exercised in interpreting the scores obtained. Thus, while the norms are not directly applicable in local contexts, the test nevertheless enables approximate comparisons with the norming sample, but more impor- 
tantly it permits comparisons within the research sample and also allows for tracking of changes in the performance of individual children over time.

\section{Fictional Narrative}

The prompt for this task was The Bear Story developed by Snow and colleagues (Snow, Tabors, Nicholson, \& Kurland, 1995). The child was presented with three pictures bound to form a book, with the following prompt: "This book has pictures but no words. I want you to look at the pictures and figure out the story they tell. When you have finished I would like you to help me write some words to go with the pictures. You tell me what the story is about and I will write it down." All narratives were audio-recorded, transcribed and then coded according to the conventions of the CHAT (Codes for the Human Analysis of Transcripts) transcription system (MacWhinney \& Snow, 1995). The narratives were coded for story structure features, content, written discourse features and key microlinguistic features associated with narratives.

\section{Word Definitions}

Following Snow et al. (1995), the ability to produce word definitions was measured using the Word Definitions subtest of the Weschler Intelligence Scale for Children (WISC-R) (Wechsler, 1974). It required the definition of 13 familiar nouns (alphabet, bicycle, bird, clock, diamond, donkey, flower, foot, hat, knife, nail, thief and umbrella). The task was introduced with a practice item as follows: "Here's a thinking game about words. When I say a word, I want you to tell me what it means. Let's try one example. The word is truck. What's a truck?" The child's response was then elaborated by saying: "Yes, a truck is something we ride in, and we can carry things in it." If the child attempted to give a nonverbal response, the examiner said: "Try to use words to explain what you mean" or "Tell about what it looks like or what it is used for". The task was audio-recorded and all responses were transcribed and coded in CHAT format (MacWhinney \& Snow, 1995). Instead of using the WISC-R scoring guidelines, the responses were coded qualitatively coded for structure and content.

\section{Analyses}

The word definition and fictional narrative data were first analysed using the Computerized Language Analysis (CLAN) programme developed at Carnegie Mellon University (see MacWhinney \& Snow, 1995 or http://childes.cmu.edu/ for details). The CLAN programme generated the frequencies for each of the codes in the word definition and narrative data, which were then entered into a data file using the Statistical Package for Social Sciences (SPSS) programme. Descriptive statistics, correlations and reliability coefficients for nine subtests (the Emergent Writing and Spelling sub-test was excluded) were computed using SPSS. The distributions of the scores for each sub-test were examined and the KolmogarovSmirnov $\mathrm{Z}$ test for normality was conducted.

\section{Ethical Considerations}

The research was approved by the Institutional Review Board of Harvard University. Recruitment letters explaining the purpose of the study were sent to all parents. The details of the commitment required were fully explained. All parents were required to provide written consent. Both parents and children were informed of their right to withdraw from the study at any time or to refuse to answer certain questions or to participate in specific activities. They were assured that data would be kept confidential and that all possible steps to protect the anonymity would be taken. There were no risks or material benefits involved in participating in the research. All children were given a small gift and a certificate of participation at the end of the study.

\section{FINDINGS}

\section{Emergent Literacy Competencies}

The descriptive statistics for nine of the ten sub-tests are presented in Table 2.

Table 2: Descriptive Statistics for the Literacy Outcome Measures $(\mathrm{n}=101)$

\begin{tabular}{|l|l|l|l|l|l|}
\hline & Mean & s. & $\begin{array}{c}\text { Max. } \\
\text { Possible } \\
\text { score }\end{array}$ & $\begin{array}{c}\text { Mean as \%ax. } \\
\text { of Max. } \\
\text { Score }\end{array}$ & $\begin{array}{c}\text { Min, } \\
\text { Max. } \\
\text { Scores }\end{array}$ \\
\hline Environmental Print & 21.36 & 7.8 & 54 & 39.6 & 7,42 \\
Concepts about Print & 7.46 & 3.4 & 24 & 31.0 & 1,16 \\
Letter Naming & 7.32 & 8.1 & 26 & 28.1 & 0,26 \\
Sounds in Words & 7.28 & 2.47 & 10 & 72.8 & 0,10 \\
Rhyme Recognition & 6.68 & 2.38 & 10 & 66.8 & 0,10 \\
Rhyme Production & 3.11 & 3.82 & 10 & 31.1 & 0,10 \\
PPVT-Standard Score & 85.3 & 10.9 & N/A & N/A & 60,11 \\
Word Definitions & 33.6 & 11.1 & N/A & N/A & 0,65 \\
Fictional Narrative & 5.19 & 3.8 & N/A & N/A & 0,22 \\
\hline
\end{tabular}

Note. For the PPVT, $\mathrm{n}=99$

\section{Environmental Print}

The mean score for this sub-test was 21.4 out of a possible 54 , while the maximum score obtained was 42 . Fifty per cent of the children scored 20 or fewer points. Only seven of the 27 test items were recognized correctly by more than $50 \%$ of the children. Evaluating performance on a test of environmental print recognition is challenging because performance is largely context dependent. The ability to recognize specific logos depends largely on previous exposure, which could vary greatly across children. Since each of the children were able to recognize at least some logos, this suggests that failure to recognize logos was due to lack of familiarity with the logo rather than a failure to attend to environmental print. Further investigation regarding the appropriate logos used for measuring environmental print recognition is needed. In addition, since environmental print is context-specific, the application of any one set of logos would only be appropriate for a limited range of contexts.

\section{Concepts about Print}

The mean score was 7.5 out of a possible 24 and the highest score obtained was 16 . Ninety per cent of participants scored 11 or fewer. More than $70 \%$ of the children were able to identify the front of a book, could tell that the story is in the print not the pictures, and knew that the left page is read before the right. Seventy-two per cent grasped the concept of a letter, whereas only $18 \%$ displayed an understanding of the concept of a word. Fewer than $50 \%$ of children demonstrated a return sweep to the left when pretending to read, were able to identify 
the first and last letters of a word, recognised when the print was upside down, and were able to match upper and lowercase letters. Not surprisingly, none of the children were able to detect changes in letter, word or line order, since few were able to read conventionally.

\section{Letter Naming}

The mean number of letters recognized by the children was seven. Thirty-four per cent of the children did not name any letters, while a further $48 \%$ were able to recognize between one and thirteen letters. Only $3 \%$ knew all the letters of the alphabet. Since systematic teaching of the alphabet is generally not part of the grade $\mathrm{R}$ curriculum, the performance of the children largely reflects informal learning and the influence of parental stimulation and high levels of letter recognition are not necessarily expected.

\section{Phonological Awareness}

On the Sounds in Words sub-test, the average score was 7.5 out of 10 . Closer examination of the scores identified that performance on identification of initial sounds was slightly better than for final sounds. Thus, the children found it easier to identify that fish and foot had the same initial sound, but had more difficulty recognising that bat and cat had the same final sound. Fifty-seven per cent of the children scored the maximum on the initial sound recognition items, whereas only $23 \%$ scored the maximum on the final sounds recognition items, suggesting that initial sounds were more salient for the children. The average score on the Rhyme Recognition sub-test was 6.7 out of 10 . The Rhyme Production subtest proved more challenging, with the average score being 3.1 and $50 \%$ of the children scoring zero. The children therefore found it relatively easy to identify that cat and hat rhyme but encountered difficulty when asked to generate words that rhyme with cat. To counteract the effects of vocabulary limitations on performance, the children were also credited for producing nonsense words. Thus a limited vocabulary need not have been an impediment to good performance. However, poor vocabulary may have been a contributing factor to poor performance for children whose strategy for approaching the task involved a combination of phonology and semantics, rather than a purely phonological one. These phonological awareness tasks seemed to pose difficulty for many children, who appeared to be unfamiliar with the task requirements. This was confirmed by classroom observations, which identified no specific focus on phonological awareness. Thus, the difficulties may reflect a lack of exposure to phonological awareness tasks rather than actual deficits.

\section{Emergent Writing and Spelling}

All but one of the children attempted writing their names: eight children produced approximate spellings and 92 were able to spell their names correctly. When asked to write anything other than their names, most children responded by saying that they could not write. Only $28 \%$ of the children attempted to write the target words in the spelling task. Because so few children attempted invented spelling, it was not feasible to use quantitative scoring.

\section{Receptive Vocabulary.}

On the PPVT III-B the mean raw score was 67.3 , which yields an age equivalent of 5 years, 2 months, whereas the mean age of the sample was 6 years, 3 months. The mean standard score obtained was 85.3. This standardised test has a mean of 100 and a standard deviation of 15 . The average performance of these participants is therefore approximately one standard deviation below the mean of the US English-speaking normative sample. Standard scores ranged from 60 , which is nearly three standard deviations below the normative mean, to 111 , which is two-thirds of a standard deviation above the normative mean. The lack of South African normative data for the PPVT and the obvious problems with using foreign norms, means that the PPVT standard score results cannot be interpreted uncritically. Nevertheless, they offer some indication of the performance of the children in comparison to other groups and can be used in comparing the children to one another or in tracking changes in individual performance over time.

\section{Fictional Narratives}

Holistic examination found that narratives ranged from minimalist narratives, with four or fewer propositions, to rather lengthy ones. The narratives typically included a strong emphasis on what Sulzby (1985) referred to as "following the action", with few story structure, written discourse and micro-linguistic features. The absence of story structure and written discourse features suggests limited exposure to written narrative. Furthermore, the dearth of micro-linguistic features and the preponderance of narrative events suggest a lack of sophistication in narrating. The narratives produced strongly resembled the children's everyday communicative use of language, characterised by contextualised use of language relying on listener background knowledge and shared physical context between speaker and listener.

\section{Word Definitions}

The children produced mainly informal definitions, which suggests that either they were not clear of the task requirements or they were not familiar with the definitional genre or both. However, since the ability to produce formal word definitions is generally regarded as a product of explicit teaching in formal school settings (Litowitz, 1977; Snow, Cancino, Gonzalez \& Shriberg, 1989), the performance of the children may be appropriate given their age and lack of formal schooling. The content of the definitions produced tended to be personalised and linked to actual experience rather than being generalized and hypothetical (Litowitz, 1977), which are regarded as the key features of good definitions. For example, a typical definition of the word bicycle would be "I ride my bicycle to the shop", rather than " $A$ bicycle is something that you ride on". The children's tendency to provide insufficient information, to use vague, non-specific words, and to gesture reflected a general difficulty in producing decontextualised language.

\section{Reliability of the data}

The Cronbach's Alpha coefficient for nine sub-tests was .74, which indicates a high degree of internal consistency within the protocol. Table 3 presents the statistics reflecting the contribution of individual sub-tests to the reliability of the protocol.

The sub-tests which contribute most to the internal consistency of the protocol are Letter Naming and PPVT, followed by Environmental Print and Concepts about Print. These are also the sub-tests which had higher internal consistency. By contrast, Rhyme Recognition and Sounds in Words, the sub-tests with the lowest internal consistency, contributed least to the internal consistency of the protocol. The Cronbach's Alpha coefficients for individual sub-tests ranged from .71 to .96, suggesting that high proportions of variance within the scores of participants are due to true score variance rather than error variance. Furthermore, the coefficients demonstrate that the participants' performance on individual items in each of these sub-tests was congruent 
Table 3: Individual Cronbach's Alpha, Item to Total Correlation and Effect on the Overall Cronbach's Alpha Coefficient of Individual Sub-tests of the ELLA

\begin{tabular}{|c|c|c|c|}
\hline & $\begin{array}{c}\text { Sub-Test } \\
\text { Alpha }\end{array}$ & $\begin{array}{l}\text { Temi } \\
\text { Total } \\
\text { Correla- } \\
\text { tion }\end{array}$ & $\begin{array}{l}\text { Aipha if } \\
\text { ftem } \\
\text { Dejeted }\end{array}$ \\
\hline Environmental Print & .79 & .46 & .74 \\
\hline Concepts about Print & .80 & .69 & .73 \\
\hline Letter Naming & .96 & .66 & .70 \\
\hline Sounds in Words & .77 & .44 & .76 \\
\hline Rhyme Recognition & .71 & .28 & .77 \\
\hline Rhyme Production & .88 & .40 & .75 \\
\hline PPVT Standard Score & $\mathrm{N} / \mathrm{A}$ & .63 & .71 \\
\hline Word Definitions & $N / A$ & .53 & .74 \\
\hline Fictional Narrative & N/A & .38 & .75 \\
\hline \multicolumn{3}{|c|}{ Alpha for the 9-subtests } & .76 \\
\hline
\end{tabular}

with their overall performance the sub-test. The high Cronbach's Alpha coefficients also indicate that sub-tests scores are not unduly influenced by performance on a few items. Twenty per cent of the narratives and word definitions were coded by an independent rater and inter-rater reliability coefficients (Cohen's Kappa) of .83 and .86 were obtained, which attests to the reliability of the coding systems for these sub-tests.

The Kolmogarov-Smirnov Z test for normality showed that scores on the PPVT, Environmental Print, Concepts about Print, and Word Definition sub-tests were normally distributed. This confirms that the sub-tests included an adequate combination of easy, medium and difficult items. However, scores for Rhyme Production and Letter Naming positively skewed, whereas scores for Sounds in Words were negatively skewed. Floor effects were observed for Rhyme Production and Letter Recognition, with $50.5 \%$ and $33.7 \%$ of participants respectively attaining scores of zero. The skewed distributions of the above sub-tests suggests that the items did not have sufficient discriminatory power and included either too many easy or difficult items. Although the Fictional Narrative scores were also positively skewed (i.e. toward lower values), because the narrative score is a summary score of a qualitative analysis of the data rather than a quantitatively scored test, the skewed distribution does not reflect discriminatory power. Instead the skewed distribution reflects the infrequent occurrence of narrative and discourse features that reflect children's awareness of the features of written language. The Rhyme Recognition scores were slightly asymmetrically distributed (the p-value associated with the KolmogarovSmirnov Z statistic was equal to .045), which means that its discriminatory value was borderline.

\section{Correlations across sub-tests}

Pearson correlation coefficients were calculated and from the correlation matrix in Table 4, it can be seen that positive inter-correlations exist among all the emergent literacy outcome variables. These correlations range from .05 to .66 , with a mean of .32. A surprising correlational relationship was the weak one between Rhyme Recognition and Rhyme Production $(r=.36, \mathrm{p}<.01)$, when a stronger one would have been anticipated. However this is indicative of the complexity of rhyme production and suggests that there are other factors beyond the ability to recognize rhymes that explain rhyme production. Essentially the literacy outcome variables displayed mild to moderate positive inter-correlations, which suggests that these skills constitute a coherent package. However, the correlations between variables are not so high as to suggest that they are measuring the same constructs.

\section{DISCUSSION}

\section{The Ella Protocol}

Although this protocol is still an experimental one, the high reliability coefficients suggest that it has potential as a comprehensive measure of emergent literacy and language development. Furthermore, the absence of floor or ceiling effects on most sub-tests indicates that for the most part these tests included a suitable combination of easy, medium and difficult items. In addition, content validity of the protocol can be argued on the basis that it was developed with reference to theoretical classifications systems for emergent literacy. Despite the floor effects on the Letter Recognition sub-test, it is a useful measure to include in view of the predictive value of letter recognition for literacy achievement (Muter, Hulme, Snowling \& Taylor, 1998). The preponderance of high scores reflected in the negatively skewed distribution of the Sounds in Words sub-test suggests that there are too many easy items on the test, whereas the floor effects on Rhyme Production task suggest that this task was too difficult for most children. These findings suggest that these tasks might not be the most best indicators of phonological awareness for this group. It is further speculated that the borderline reliability coefficients for Rhyme Recognition and the low correlation with Rhyme Production may be ascribed to children guessing correct answers. A measure of rhyming ability would nevertheless serve as an important indicator of general phonological awareness, whereas substitution of the Sounds in Words sub-test with a more challenging phoneme awareness task such as phoneme isolation (e.g. What is the first sound you hear in the word 'cat'?) or segmentation (e.g. Clap once for each sound you can hear in the word 'cat') would tap into a higher level of phonological awareness. ii This would be particularly important for identifying children who exhibit general phonological awareness but not phoneme awareness. Attempts to develop a formal scoring system for emergent writing and spelling proved difficult due to the fact that only $28.2 \%$ of the children attempted to spell. However, since it is nevertheless

Table 4: Correlation Matrix for Emergent Literacy Outcomes ( $n=98-101)$

\begin{tabular}{|c|c|c|c|c|c|c|c|c|c|c|}
\hline & Sub-Test & 1 & 2 & 3 & 4 & 5 & 6 & 7 & 8 & 9 \\
\hline 1 & Letter Naming & 1.0 & & & & & & & & \\
\hline 2 & Sounds in Words & $\underset{\star \star \star \star \star}{.44}$ & 1.0 & & & & & & & \\
\hline 3 & Rhyme Recognition & .12 & $.53^{\star \star}$ & 1.0 & & & & & & \\
\hline 4 & Rhyme Production & $.34^{\star \star}$ & $.39^{\star *}$ & $.36^{* \star}$ & 1.0 & & & & & \\
\hline 5 & Concepts about Print & $\begin{array}{l}.66 \\
\star \star \star *\end{array}$ & $.38^{\star \star}$ & $.29^{\star \star *}$ & $.33^{\star \star}$ & 1.0 & & & & \\
\hline 6 & Environmental Print & $.54^{\star \star}$ & $.26^{\star *}$ & .04 & .06 & $.43^{\star \star}$ & 1.0 & & & \\
\hline 7 & PPVT STD & $.53^{\star \star}$ & $.29 * *$ & $.20 *$ & $.26^{\star \star}$ & $.55^{\star \star}$ & $.39 * *$ & 1.0 & & \\
\hline 8 & Word Definitions & $.39^{\text {**}}$ & $.33^{\star \star}$ & $.25^{*}$ & $.33^{\star \star}$ & $.33^{* \star}$ & $.29 * *$ & $.42^{\star \star}$ & 1.0 & \\
\hline 9 & Fictional Narrative & $.25 *$ & .10 & .16 & $.25^{*}$ & $.35^{\star *}$ & $.20 \sim$ & $.34 * *$ & $.18 \sim$ & 1.0 \\
\hline
\end{tabular}


important to obtain some indication of a child's writing ability, it is suggested that an informal writing sample be obtained during assessment.

It is further suggested that the measurement of phonological awareness be adapted to include higher level phonological awareness skills and that the protocol should be refined by conducting an item analysis, followed by substitutions for problematic items. Further pilot testing of the instrument is then recommended.

\section{The Children's literacy Competencies}

The performance of the children on the ELLA shows that these children from historically disadvantaged backgrounds do indeed possess a reasonable repertoire of literacy skills and knowledge as they prepare to enter first grade. The children could recognize environmental print and understand basic concepts about print. Most children were able to identify words with the same onset or rime, but had considerable difficulty generating words with similar rimes. They were only able to recognize and name a small number of letters of the alphabet, which is understandable given that the teaching of the alphabet was not part of the curriculum. The difficulties in the areas of phonological awareness and letter knowledge may be related to the fact that these skills are not developed in the course of their daily school experiences. Whereas attention to environmental print and concepts about print can develop as secondary consequences in the context of participating in activities other than literacy or by observing others, letter knowledge and phonological awareness require much more explicit and structured exposure. All except one child were able to write their own name and a small percentage was able to spell phonetically regular words. Assessment of their discourse skills identified that in general, they had difficulty producing language with a high degree of lexical and syntactic explicitness. They either assumed too much background knowledge on the part of a listener or were simply not able to provide sufficient background to the listener.

The children's emergent literacy competency profiles suggest that they possess adequate skills to support acquisition of print decoding skills necessary for fluent reading. However, they display weaknesses in the decontextualised language skills that have been found to support later reading comprehension (Tabors, Snow \& Dickinson, 2001). This suggests that while they are likely to have adequate skills for decoding print, which is largely the focus of reading instruction in grade 1 , as the instructional focus shifts from decoding to reading comprehension, if their decontextualised language skills have not been developed further, it is likely that their reading comprehension may be compromised.

On both the word definitions and fictional narrative tasks the children displayed a tendency to provide insufficient information, to use vague, non-specific words, and to use gesture. Their limited use of lexically and syntactically explicit language suggests that they have not developed an awareness of differences between oral and written language, perhaps due to limited exposure to written narrative. While it can be argued that the children are more exposed to the oral storytelling tradition, interviews with parents revealed that parents of children in these communities are more likely to read to their children than to engage in oral storytelling. Thus, it seems that the problem for these children is not lack of but rather insufficient exposure to written narrative. Both the word definitions and narrative production tasks revealed the children's difficulty in producing language that is lexically and syntactically explicit and not reliant on listener background knowledge or contextual cues.

Although international research has shown that the acquisition of decontextualised language skill presents a challenge for all children (Hemphill \& Snow, 1996), the challenge may be even greater for these children, many of whose parents do not have English as a first language. Although the children had reasonable exposure to print, their opportunities for language stimulation in particular were limited in both the home and school contexts. As indicated earlier, many of the parents were not first language speakers of English and approximately half had had Afrikaans as the primary language in their own families of origin. However, even the children who were raised in homes where English was the primary or only language spoken, were not being exposed to standard South African English linguistic models. Similarly, the children had restricted opportunities for exposure to rich language and literacy experiences in their classroom contexts. Although both the home and school contexts of the majority of these children do offer opportunities for engaging with literacy artefacts and activities, these opportunities tend to be geared towards developing print awareness rather than fostering the decontextualised language skills which support literacy.

Although the average findings are the main focus of this description of the children's literacy skills, there was variation in performance. The top performers were able to recognise all the letters of the alphabet, spell a few sight words correctly and produce invented spellings closely approximating the target word. By contrast, one of the lowest performers was unable to spell his name correctly and was only able to recognise two letters of the alphabet. Although it would not be appropriate to establish norms for emergent literacy skills, assessment at grade $\mathrm{R}$ level or upon commencing grade 1 would be useful for planning instructional activities. In addition, benchmarks could also be identified to assist in identifying children with limited literacy skills and concepts who would require an orientation to literacy prior to formal reading instruction. The average skill profile of the children suggests that an optimal grade 1 instructional environment for them should include a strong focus on developing letter knowledge and phonological awareness skills and extensive opportunities for developing decontextualised language skill. To develop the decontextualised language skills necessary for children's encounters with written text, teachers need to create scaffolded conversational interactions with children that entail recounting past events, planning future events, providing explanations, and engaging in pretend play which involves verbalizing roles and actions (Dickinson, 1991). The key features of scaffolded conversational interactions should be multiple utterances and/or multiple speaker turns pertaining to the same topic and conversational topics about phenomena or events outside of the current classroom communication setting (Dickinson, 1991). Recent findings have shown that kindergarten children displayed better print-related concepts and decontextualised language skills when their classroom conversations with teachers included "personal narratives, talk about past and present events, and discussion of ideas" (Dickinson, 2001, p. 251). Although the National Curriculum Statement (Department of Education, 2002) emphasises listening, speaking, reading and writing throughout the foundation phase, it is not clear to what extent this is practised in classrooms. It appears that teachers on the ground do not have fully developed understandings of the importance of language in literacy development and are often not able to create classroom environments that provide rich language stimulation for learners. In the Western Cape for example, only $12 \%$ of ECD practitioners have university training in 
early childhood, $38 \%$ have informal training and $27 \%$ have no training (Department of Education, 2001).

It is critical that the role of language in literacy development be emphasised in pre-service teacher training as well as continuing professional development for teachers. Speech-language therapists working within the education department have the potential to make an important contribution with regard to training in-service teachers to create language-rich classroom environments, yet they are a resource that is not being sufficiently utilised.

Since the sample for the research was purposively selected, no claims about the representativeness of either the sample or the findings can be made. However, it can be argued that these children and their particular school contexts are mostly similar to other children and school contexts in their neighbourhoods. Thus, the findings could give a reasonably accurate indication of the emergent literacy skills of learners in similar historically coloured urban neighbourhoods. Although the emergent literacy competencies displayed by the children showed promise in terms of literacy development, these children were not from the most poor families and communities in the country, nor were the schools among the least resourced. It is therefore not unreasonable to speculate that the picture in more impoverished contexts would reflect even greater difficulties with emergent literacy competencies. In the light of the extensive cultural diversity and the vast disparities in opportunities and resources, it would be important to study the literacy competencies in other South African socio-cultural contexts. Moreover, since the majority of early childhood programmes in South Africa are not school-based and the quality of schoolbased early childhood programmes is generally better than community-based programmes (Department of Education, 2001), this implies that most children of grade $\mathrm{R}$ age experience literacy development contexts that are less favourable than those experienced by these participants. Thus, most children entering grade 1 in South Africa are likely to commence formal schooling with a more limited repertoire of skills than those displayed by the participants in this study. Although there are policies such as the National Curriculum and the National Literacy Strategy in place, it is imperative that a concerted effort be made to ensure that these are effectively implemented. Unless children are provided with the resources and opportunities to acquire literacy, they will remain at the threshold of the doors of learning.

\section{ACKNOWLEDGMENTS}

This research was conducted as part of my doctoral studies, which were generously funded by the Fulbright South Africa Programme, the Spencer Foundation, and the Harvard University Graduate School of Education. Partial funding for the data collection was also provided by the University of the Western Cape. The contributions of Catherine Snow and Lowry Hemphill to my intellectual development in general and this research in particular are gratefully acknowledged. Finally, thanks to Seppo Tuomi for his helpful comments on earlier drafts of this article.

\section{REFERENCES}

Barton, D. (1994). Literacy: An introduction to the ecology of written language. Oxford, UK Basil Blackwell.

Barton, D. \& Hamilton, M. (1998). Local literacies: Reading and writing in one community. London: Routledge.

Bear, D., Invemizzi, M., Templeton, S. \& Johnston, F. (2000) Words their way: Word study for phonics, vocabulary and spelling instruction ( $2^{\text {nd }}$ ed.). Ohio: Prentice Hall.

Bradley, L. (1990). Rhyming connections in learning to read and spell. In P.D. Pumfrey and CD Elliott (Eds.), Children's difficulties in reading, spelling and writing (pp. 83-100). U.K.: Falmer Press.

Bradley, L. \& Bryant, P.E. (1983). Categorising sounds and leaming to read - A causal connection. Nature, $301,419-521$.

Clay, M.M. (1966). Emergent reading behaviour. Unpublished doctoral dissertation. University of Auckland, Auckland, New Zealand.

Clay, M.M. (1979). The early detection of reading difficulties ( ${ }^{\text {nd }}$ ed.). Auckland, NZ: Heineman.

Clay, M.M. (2000). Follow me, Moon. Portsmouth, NH: Heinemann.

Department of Education (2001). The nationwide audit of ECD provisioning in South Africa. Pretoria, South Africa: Department of Education.

Department of Education (2002). The National Curriculum Statement. Pretoria: South Africa: Department of Education.

Department of Education (2003). Systemic Evaluation Foundation Phase Mainstream. Pretoria: South Africa: Department of Education.

Dickinson, D.K. (1991). Teacher stance and setting: Constraints on conversation in pre-schools. In A.. McCabe and C. Petersen (Eds.), Developing narrative structure _(pp. 255 - 301). Hillsdale, N.J.: Lawrence Erlbaum.

Dickinson, D.K. (2001). Large-group and free-play times: Conversational settings supporting language and literacy development. In D. Dickinson and P. Tabors (Eds.), Beginning literacy with language (pp. 223 - 255). Baltimore: Brookes.

Dunn, L.M. \& Dunn, L.M. (1997). Peabody Picture Vocabulary Test. Third Edition (PPVTIIIB). Circle Pines, MN: American Guidance Service.

Goswami, U. \& Bryant, P.E. Phonological skills and learning to read. London: Erlbaum.

Gunn, B., Simmons, D. \& Kameenui, E. (1998). Emergent literacy: Research bases. In D. Simmons and E.A. Kameenui (Eds.), What reading research tells us about children with diverse learning needs (pp. 19 - 50). Mahwah, NJ: Erlbaum.

Hemphill, L. \& Snow, C. (1996). Language and literacy development: Discontinuities and differences. In D. Olson and N. Torrance (Eds.), Handbook of education and human development: New models of learning, teaching and schooling. Cambridge: Blackwell.

Litowitz, B. (1977). Leaming to make definitions. Journal of Child Language, 4, 289-304.

Lomax, R. \& McGee, L. (1987). Young children's concepts about print and reading: Toward a model of reading acquisition. Reading Research Quarterly, 22 (2), 237-256.

MacWhinney, B. \& Snow, C. (1995). The CHILDES Project: Tools for analyzing talk. NJ: Lawrence Erlbaum.

Mason, J. (1980). When do children begin to read: An exploration of four year old children's letter and word reading competencies. Reading Research Quarterly, 15 (2), 203-227.

Mason, J.M. \& Stewart, J.P. (1990). Emergent literacy assessment for instructional use in kindergarten. In L.M. Morrow and J.K. Smith (Eds.), Assessment for instruction in early literacy (pp. 155175). Englewood Cliff, N.J.: Prentice-Hall.

Muter, V., Hulme, C., Snowling, M. \& Taylor, S. (1998). Segmentation, not rhyming, predicts early progress in leaming to read. Journal of Experimental Child Psychology, 71, 3-27.

Snow, C.E, Cancino, H., Gonzalez, P. \& Shriberg, E. (1989). Giving formal definitions: An oral language correlate of school literacy. In D. Bloome (Ed.), Classrooms and literacy (pp. 233 -249). New Jersey: Ablex.

Snow, C.E., Tabors, P.O., Nicholson, P. \& Kurland, B. (1995). SHELL: Oral language correlates and early literacy skills in kindergarten and first grade children. Journal of Research in Education, 10 (1), 37 - 48. 
Sulzby, E. (1985). Children's emergent reading of favourite storybooks: A developmental study. Reading Research Quarterly, 20 (4), 458 - 481.

Sulzby, E. \& Teale, W.H. (1991). Emergent literacy. In R. Barr, M.L. Kamil, P. Mosenthal and P.D. Pearson (Eds.), Handbook of reading research (Vol. 2) (pp. 727 - 757). New York: Longman.

Tabors, P.O., Snow, C.E. \& Dickinson, D.K. (2001). Homes and school together: Supporting language and literacy development. In D. Dickinson and P. Tabors (Eds.), Beginning literacy with language (pp. 313 - 334). Baltimore: Brookes.

Teale, W.H. \& Sulzby, E. (1986). Introduction: Emergent literacy as a perspective for examining how children become writers and readers. In W. Teale and E. Sulzby (Eds.), Emergent literacy: Writing and reading (pp. vii xxv). New Jersey: Ablex.
Wechsler, D. (1974). Wechsler Intelligence Scale for Children-Revised. New York: The Psychological Corporation.

Western Cape Education Department (2007). Grade 3 literacy and numeracy results. Media release. Retrieved September 18, 2007 from http:// wced.wcape.gov.za/comms/press/2007/49_gr32006.html

Whitehurst, G. \& Lonigan, C. (1998). Child development and emergent literacy. Child Development, 69 (3), 848-872.

Willenberg, I.A. (2004). Getting set for reading in the rainbow nation: Emergent literacy skills and literacy environments of kindergarteners in South Africa. Unpublished doctoral dissertation. Harvard University, Cambridge, Massachusetts, USA.

\section{APPENDIX A}

\section{Stimuli for Sound in Words}

\begin{tabular}{|l|l|}
\hline \multicolumn{1}{|c|}{ Word Initial Sounds } & \multicolumn{1}{|c|}{ Word Final Sounds } \\
\hline cat ball bag & fan bat cat \\
bath tie boy & car fish star \\
man cow milk & snake cake rain \\
sheep road ring & keys trees leaf \\
fish dog foot & wall ball bat \\
\hline
\end{tabular}

\section{APPENDIX B}

\section{Stimuli for Rhyme Recognition and Production}

\begin{tabular}{|l|l|}
\hline \multicolumn{1}{|c|}{ Rhyme Recognition } & \multicolumn{1}{|c|}{ Rhyme Production } \\
\hline cat hat ring & cat hat \\
moon spoon dog & pet wet \\
cot cap tap & sun gun \\
cone cake bone & glad mad \\
sun bin gun & map gap \\
train rain rake & \\
bat coat boat & \\
clock sun sock & \\
wall ball bird & \\
duck truck cup & \\
\hline
\end{tabular}

Note

${ }^{\mathrm{i}}$ lt is acknowledged that the use of racial labels is a contentious issue. However, since the developmental contexts of the participants have been inexorably shaped by apartheid, it is considered important to identify this group by their racial designation.

"Contrary to the earlier evidence of Bradley and Bryant (1983) and Goswami and Bryant (1990) for the predictive value of rhyming ability for reading,

Muter et al. (1998) found that segmentation, not rhyming ability predicted reading during the first year of schooling. However, rhyming ability was found to be a predictor of spelling ability in the second year of schooling. 